\title{
Monitoring Day and Night-Time Situation of Urban Heat Island and Possible Adaptation Measures in Douala, Cameroon
}

\author{
Mbia Ekolok Awuh \\ Department of Geography \& Planning, The University of Bamenda (UBa), Bamenda, Cameroon \\ Email: awuhekolok@yahoo.co.uk
}

How to cite this paper: Awuh, M. E. (2021). Monitoring Day and Night-Time Situation of Urban Heat Island and Possible Adaptation Measures in Douala, Cameroon. Journal of Geoscience and Environment Protection, 9, 163-176.

https://doi.org/10.4236/gep.2021.98011

Received: February 25, 2021

Accepted: August 23, 2021

Published: August 26, 2021

Copyright $\odot 2021$ by author(s) and Scientific Research Publishing Inc. This work is licensed under the Creative Commons Attribution International License (CC BY 4.0).

http://creativecommons.org/licenses/by/4.0/

\begin{abstract}
Urban Heat Island (UHI) has the potential to directly influence the health and welfare of urban residents. The study employed a traditional method called "paired measurement program" to analyze the effects of four land use/landcover patterns on intra-urban air temperature variations in the Douala Metropolis, Cameroon under different atmospheric conditions. This study also investigated the possible adaptation measures employed by the inhabitants to combat the urban heat island effects. The result revealed a variation in the temperature of the selected transects. There was a mix of cool and heat islands by day, especially during rainy seasons. The daytime variations were strongly correlated to the amount of tree shading. It was also observed that the temperature gradient was formed at the Central Business District (CBD) and progressively lowered to the suburbs. The thermal comfort classification for the area ranges between $25.4^{\circ} \mathrm{C}$ and $27^{\circ} \mathrm{C}$, which is a class where over $50 \%$ of the population feels stressed; and the range of $32^{\circ} \mathrm{C}$ and above, where most of the population suffers discomfort. In order to investigate the possible adaptation measures employed by the inhabitants of Douala, two hundred and fifty questionnaires were distributed and analyzed using descriptive statistics. The result revealed that the inhabitants use various coping strategies in order to adapt to UHI effects. The strategies identified include; stay indoors, drink plenty of water, wear light clothing, go to an A/C location, take a cool shower, avoid outdoors, and wear a hat or cover head. The widely used coping strategy identified is drinking plenty of water. The expensive nature of $\mathrm{A} / \mathrm{C}$ makes it the least used coping strategy.
\end{abstract}

\section{Keywords}

Surface Modifications, Increase Temperature, Coping Strategy 


\section{Introduction}

Science has determined that any city with a significant amount of surface modification experiences increased urban temperatures (Harlan et al., 2006). When urban areas develop, open-land and vegetation are replaced by industrial landscapes and infrastructure which include: buildings, skyscrapers, houses, cement sidewalks and paved roads. These structures absorb heat and subsequently warm their surroundings (Awuh et al., 2018). Building density also contributes to the increased city temperatures. The majority of most buildings' surface area does not face open-air or spaces, instead, they generally face other warm buildings with heat becoming trapped in the city. The trapped heat is then released during nocturnal times, and temperatures remain elevated into evenings and nights. Thus, make cities become efficient heat incubators (Oke, 1997). This peak in temperature is most pronounced within 3 to 5 hours after sunset. The experienced elevated urban temperature, when compared to surrounding rural areas, is what constitutes an Urban Heat Island. Nighttime elevation of temperatures causes the most harm to urban dwellers (Enete et al., 2014). This increase in temperature within urban cores, when compared to adjacent rural and suburban areas, has been coined as the Urban Heat Island (UHI).

Urban Heat Island (UHI) has the potential to directly influence the health and welfare of urban residents. The most important negative consequences of UHI are related to increased temperatures in urban territories, and especially higher risks of heatwaves and their effects (including increased mortality and morbidity of urban inhabitants), human discomfort, increased energy consumption during summertime (although reduced during winters), impaired air and water quality (Gartland, 2010) and other adverse impacts (Hsieh \& Huang, 2016; Buchin et al., 2016; Baker et al., 2002). Heatwaves are one of the major risk factors of UHI as they can affect human health resulting in exhaustion, dehydration, circulatory disorders, and potentially death (Gartland, 2010). Heatwaves primarily pose a danger to vulnerable individuals, such as elderly people, the very young, those with social or physical impairments, or those unable to afford mitigation measures (such as air conditioning) (Rebetez et al., 2009; Ruddell et al., 2010). In the most recent national data, $45 \%$ of deaths were to individuals over the age of 65 (Centers for Disease Control and Prevention, 2003). Although thermoregulatory systems of the elders are developed, they may be damaged or impaired. Elders are more "susceptible to heat related illness (Enete et al., 2014) because they are not often able to maintain hydration" elders, like children, have a high sweat threshold that prevents their body from adapting to increases in temperature (Basu \& Samet, 2002).

In Douala, dry season, urban heat islands create a myriad of unmanageable consequences for low-income peoples and families (Enete et al., 2014). Increased energy consumption and emissions of pollutants bolster heat-related illnesses. While businesses and the middle and upper class are safely nestled inside airconditioned spaces, many low-income persons cannot afford to turn on, let 
alone own, air conditioning units. The aim of this study is to access the coping strategies adopted by the inhabitants of Douala, Cameroon to combat the urban heat island effect.

\section{Materials and Methods}

\subsection{Study Area}

The study area is Douala the capital Douala Metropolis is located on the southwest coast of Cameroon at an altitude of about 1 meter and lies on $4.05^{\circ}$ Nord latitude, $9.71^{\circ} \mathrm{EST}$ longitude. It is one of the well-known cities in Cameroon and it is home to the largest port and international airport. Douala, being the commercial capital of the country; manages most of the city's largest market. The city covers a surface area of approximately $850 \mathrm{~km}^{2}$. The location of Douala puts it firmly within the tropics with high Solar all year round. Douala has sunshine duration averaging 1.3 hours per day in August and 5.0 hours per day in April with approximately 1274 sunshine hours annually. The climate indicates a region of high temperature and rainfall that are almost evenly, spread throughout the year. Mean daily temperatures drop by about $2^{\circ} \mathrm{C}-3^{\circ} \mathrm{C}$. Douala receives on average $4114 \mathrm{~mm}$ (162.0 in) of precipitation annually or $343 \mathrm{~mm}$ (13.5 in) each month. The month with the driest weather is December. The month with the wettest weather is August with a total of $775 \mathrm{~mm}$ of rain. Mean relative humidity for an average year is recorded as $729.8(\%)$ and on a monthly basis; it ranges from $74 \%$ in January to $86 \%$ in July.

\subsection{Research Methods}

The study adopted survey research design since it seeks to solve existing problems in the environment. In order to access the urban heat island situation and possible coping strategies adopted by the inhabitants of Douala, the researcher employed primary and secondary sources of data collection.

\subsection{Sample Site Selection}

Two land-use classes (resident and commercial) and two land-cover types (paved and green surfaces) were used for the selection of the sample sites. The characteristics used for the selection of these Sample sites include; availability of industries, degree of vegetation cover, population density of the area, nature of residential area, growth rate of the area in terms of development, land use category, potential of evaporation. Field observation was equally carried out to identify the different land uses in the Douala urban space to correlate their relationship to UHI. The different land uses identified were used as a yardstick in the selection of the sample sites.

Based on the aforementioned, the following land-use/land covers were selected based on purposive sampling.

1) High-density, high rise, non-residential areas with low greenery (DTL);

2) Low building density, low-rise, residential areas with high greenery (HDR); 
3) Medium density, mixed residential (some residential, some commercial institutional) area with a greenery extent between (1) and (2) above (NW2);

4) Areas with similar land use, building density and greenery, one having more fully developed vegetation canopy than the other (LVR and LOR).

A search for locations with these characteristics resulted in the selection of the following sites:

1) DTL (Downtown location) = Akwa South (CBD), stories accompanied by heavy traffic, high degree of paved areas and little or no greenery;

2) HDR (High-density Residential Site) = Bonapriso. Residential areas with low traffic volume and heavy presence of mature vegetation;

3) NW2 (Multi-family Residential/Institutional Site) = Bassa, Bonaberi industrial, residential/commercial area with substantial parking lots;

4) LVR (Low-density Vegetated Residential Neighborhood) = Bonanjo;

5) LOR (Low-density Open-Canopy Residential Neighborhood) = Bonamousadi.

\subsection{Paired Measurement Program}

During the study, network of sensors was set up over Douala urban space in 20212 to measure air temperature. Temperatures were measured simultaneously in all transects that were superimposed on the study area. The data was collected in two sessions. The first session covered the months of February, March, representing the dry season while the second session ran from June to July representing the rainy season. Air temperature in the Douala urban space was measured simultaneously with the help of a digital thermometer at each experimental site and a reference station was set up at an open area located near a large open grass field on the side of the Douala International Airport. In close proximity to the reference station is a fully featured weather station maintained by the Douala International Airport.

The digital thermometer (KT300) was used as a measurement probe due to its good performance outdoors. The digital thermometer was placed in a naturally ventilated, insulated plastic box to block direct radiation. Probes used at the reference station and other urban sites were shaded similarly. The shielded probe was sited at an open area approximately $1.5 \mathrm{~m}$ above ground. Test run was performed by running each shielded probe assembly for three days and comparing the temperature reading against the weather station data at the airport. The surrounding was classified as low-density institutional land-use with a stretch of plain terrain significant grass cover and some paved (parking lot) areas due to its more or less rural like nature, the difference between a location's air temperature and that at the reference station was considered to be the effect of urbanization at the said station.

\subsection{Questionnaire}

To investigate the coping measure adopted by the inhabitants of Douala, household interview was conducted between February and July 2012 and question- 
naires were administered. 50 semi-closed questionnaires were administered using random sampling techniques in each of the selected sample sites giving a total of 250 questionnaires. The questionnaires were administered using a random sampling technique. The survey questions were close ended with multiple-choice responses where respondents could select multiple responses, all answer choices were listed out as separate variables. The questions were directed towards the adaptive measures or responses used by the people to reduce heat related diseases. The coping measures included; staying indoors, drink plenty of water, seeking shade, wearing light clothing, wearing a hat/covering head, going to air conditioned place, reducing activity, takes cool showers, and avoiding outdoor activity. To assess the effectiveness of coping or adaptive measures in lowering the prevalence of self-reported heat-related symptoms and illnesses, each household was given a score for coping ability.

In order to limit the effects or shortcomings of questionnaires which include poor or wrong interpretation of questions, a face-to-face administration of questionnaires was done during which the resource persons helped the respondent to interpret the questions need be. In neither cases where the respondent could neither read nor write, questions and responses were read out to the respondents for him or her to choose the best response. Since the questionnaires were prepared in English and the vast nature of the study area made administration of the questionnaire difficult, 5 persons (who are bilingual) were selected and trained on how to administer the questionnaire in the five sample sites selected for the study. The researcher constantly monitored the trained person in the field to ensure that they are doing the right thing.

\subsection{Urban Heat Island Assessment}

During the study period, transect and fixed point temperature measurements were taken hourly and averaged over a month. Then, the urban heat island was assessed using Equation (1).

$$
\mathrm{UHI}=T_{U}-T_{R}
$$

where: $\mathrm{UHI}=$ Urban Heat Intensity; $T_{U}=$ Temperature at urban station; $T_{R}=$ Temperature at rural station.

\subsection{Spearman's Rank Correlation}

Spearman's rank correlation analysis of the form below was employed to correlate land-use/land-cover and temperature (Equation (2)).

$$
R=1-\frac{6 E d_{i}^{2}}{n\left(n^{2}-1\right)}
$$

where: $n=$ number of variables; $E=$ summation; $d^{2}=$ square of the difference.

\section{Result Presentation and Discussion of Findings}

This section presents the results and findings of objective one and two which seeks to determine the spatial extent and magnitude of urban heat Island for 
Douala urban space and possible adaptive measures. The results are presented using graphs, charts, tables and pictures.

\subsection{Urban Heat Island Situation in Douala}

The urban heat island situation in Douala varies considerablely from one area to another due to variation in land use type and pattern and from dry season to rainy season due to change in climatic elements.

\subsubsection{Dry Season Situation (Day-Time)}

The Dry season months showed strong variability in temperature in the different transects selected for the study. Temperature variability was high especially between day and night (Table $1 \&$ Table 2).

The result shows that the heavily vegetated urban residential sites (HDR) and suburban sites (LOR) with fully developed vegetation canopy were the coolest with -3.0 and -1.70 respectively. This is because the tree cover act as shade limiting the amount of sunlight that reaches the ground. The hour-to-hour variation in air temperature during daytime was significant. It was also observed that the magnitude of the temperature differences decreased as background climate become hotter. During the day, very few cool Islands were observed. The thick vegetated areas of GRA record few days of urban cool Islands. The extensive tree canopy of the vegetated sites produced cooling during the day. The peak temperature value was recorded between $1300 \mathrm{hrs}$ and $1500 \mathrm{hrs}$.

\subsubsection{Dry Season Situation (Night-Time)}

Unlike the daytime, nighttime temperature showed a clear downtown-cantered heat Island. Table 2 clearly depicts this variation.

Table 1. Temperature variation during the day.

\begin{tabular}{cc}
\hline Site location names & Temperature variation \\
\hline DTL Akwa south (CBD) & +2.5. \\
LOR Bonamousadi & -1.70 \\
LVR GRA (Bonanjo) & +1.5 \\
NW2 Bassa, Bonaberi & +4.0 \\
HDR Bonapriso & -3.0
\end{tabular}

Table 2. Temperature variation during the night.

\begin{tabular}{cc}
\hline Site location names & Temperature variation \\
\hline DTL Akwa south (CBD) & +2.3 \\
LOR Bonamousadi & +0.3 \\
LVR Bonanjo (GRA) & +0.8 \\
NW2 Bassa, Bonaberi & -2.2 \\
HDR Bonapriso & +0.4
\end{tabular}


The result of this study revealed that all residential sites were warmer than the reference site (from 0.3 to 0.8 cooler) while the downtown location was up to $2.3^{\circ} \mathrm{C}$ warmer (Table 2). Thus, resulting to a maximum night-time air temperature heat Island of about $2.3^{\circ} \mathrm{C}$ during the study period where as the industrial areas was cooler than the reference site $(-2.2)$. The highest night-time intra-urban air temperature difference was observed during early evening period ( $1500 \mathrm{hrs}$ to 2300 hrs).

\subsection{Urban Heat Island Magnitude}

From the data collected, the difference between the inner city temperature and that of outskates was measured. The average daily temperature and the daily temperature range for each of the sites were compiled using the hourly temperature measurements. These averages were used to determine the site-specific average dry season and rainy season temperatures defined by the months of February/March and June/July (Table 3). Using the reference site as the outskirt and the urban city site as the inner city, the study revealed a decrease in the urban temperature as one move away from the city Centre. The result shows that urban heat Island magnitude generally increases with increasing air temperature with its peak intensity in the late evening and early night. The range of magnitude across the study area was observed to $2.27^{\circ} \mathrm{C}$ maximum heating observed around the urban core and in areas where human activities are concentrated.

Using the reference site as the outskirt and the urban city site as the inner city, it is observed that the urban temperature decreases as one move away from the city centre. The result shows that urban heat Island magnitude generally increases with increasing air temperature. On a daily basis, the UHI reaches its peak intensity in the late evening and early night. The range of magnitude across the study area (spatial range) is $2.27^{\circ} \mathrm{C}$ with maximum heating in the urban core and generally busy areas where human activities are concentrated.

\subsection{Test of Hypothesis}

The hypothesis is stated as thus: "There is no significant difference in land surface temperature between the urban and rural stations selected in the Douala Metropolis, Cameroon”. To determine the significant differences, a Spearman

Table 3. Monthly mean temperatures for reference station ( $r$ ) and urban sites $(\mathrm{u})$ reported as a spatial average $(\mathrm{Tm} \mathrm{u}-\mathrm{r})$.

\begin{tabular}{cccc}
\hline Monthly & Urban Sites $(\mathrm{u})$ & Reference Site $(\mathrm{r})$ & $\mathrm{Tm} \mathrm{u}-\mathrm{r}$ \\
\hline February & $31.3^{\circ} \mathrm{C}$ & $28.8^{\circ} \mathrm{C}$ & $2.5^{\circ} \mathrm{C}$ \\
March & $32.10^{\circ} \mathrm{C}$ & $28.5^{\circ} \mathrm{C}$ & $3.6^{\circ} \mathrm{C}$ \\
June & $29.87^{\circ} \mathrm{C}$ & $27.0^{\circ} \mathrm{C}$ & $2.87^{\circ} \mathrm{C}$ \\
July & $28.67^{\circ} \mathrm{C}$ & $26.4^{\circ} \mathrm{C}$ & $2.27^{\circ} \mathrm{C}$ \\
Feb-July & $30.49^{\circ} \mathrm{C}$ & $27.68^{\circ} \mathrm{C}$ & $2.9^{\circ} \mathrm{C}$ \\
\hline
\end{tabular}


rank order correlation was done between Land Use and Temperature in the selected transects (Table 4).

In other to perform this task, the students't test was employed. The test was carried out at $95 \%$ level of confidence. The result revealed the calculated value of 6.5 is greater than the table value 1.86 . Thus, indicating a strong correlation between built up areas and temperature in the Douala Metropolis of Cameroon.

\subsection{Implication of UHI to Human Health in Douala Metropolis}

To examine the effect of UHI on the health of the inhabitant in Douala, the comfort index was calculated using temperature-humidity index (THI) and the result was compared with table used by (Besancenot, 1978; Tzenkova et al., 2003) as seen in Table 5 and Table 6.

The mean annual THI results in degrees Celsius from 2001-2011 for Douala Metropolis was calculated. It was observed that the range of its variation per month for the ten years' data from January to December was within the range of

Table 4. Rank-order correlation of land use (x) and Temperature for selected Areas of douala metropolis. Temperature values (y).

\begin{tabular}{cccccc}
\hline Land use $(\mathrm{x})$ & Temperature $(\mathrm{y})$ & Rank $(\mathrm{x})$ & Rank $(\mathrm{y})$ & $\mathrm{D}$ & $\mathrm{D}^{2}$ \\
\hline Akwa & 37.1 & 2 & 6 & -4 & 16 \\
Bonaberi & 38.8 & 1 & 9 & -8 & 64 \\
Bonapriso & 36.5 & 6 & 5 & 1 & 1 \\
Bonanjo & 35.4 & 5 & 2 & 3 & 9 \\
Brazzaville & 38.9 & 9 & 10 & -1 & 1 \\
Bassa & 38.2 & 3 & 8 & -5 & 25 \\
New bell & 36.4 & 7 & 4 & 3 & 9 \\
Youpwe & 36.2 & 8 & 3 & 5 & 25 \\
Congo & 37.2 & 4 & 7 & -3 & 9 \\
Bonamousadi & 34.1 & 10 & 1 & 9 & 81 \\
\hline
\end{tabular}

$\Sigma 240$.

Table 5. Classification of Discomfort Index (DI).

\begin{tabular}{ccc}
\hline $\mathrm{N}$ & Thermo-Hydrometric Discomfort Index Class & $\mathrm{DI} /{ }^{\circ} \mathrm{C}$ \\
\hline 6 & Very Cold & $\mathrm{DI} \leq-1.7$ \\
5 & Cold & $-1.7<\mathrm{DI}<12.9$ \\
4 & Cool & $13.0 \leq \mathrm{DI}<14.9$ \\
3 & Comfortable & $15.0 \leq \mathrm{DI} \leq 19.9$ \\
2 & Hot & $20.0 \leq \mathrm{DI} \leq 26.4$ \\
1 & Very hot & $26.5 \leq \mathrm{DI} \leq 29.9$ \\
0 & Torrid & $\mathrm{DI} \leq 30.0$
\end{tabular}

Source: Adopted from (Besancenot, 1978). 
Table 6. Classification of Discomfort Index (DI).

\begin{tabular}{ccc}
\hline $\mathrm{N}$ & Thermo-Hydrometric Discomfort Index Class & $\mathrm{DI} /{ }^{\circ} \mathrm{C}$ \\
\hline 1 & No discomfort & $>21$ \\
2 & Under 50\% of the population feels discomfort & $21-24$ \\
3 & Over 50\% of the population feels discomfort & $24-27$ \\
4 & Most of the population feels discomfort & $27-29$ \\
5 & Everyone feels stress & $30-32$ \\
6 & State of medical emergency & $>32$ \\
\hline
\end{tabular}

Source: (Tzenkova et al., 2003).

1.6 to 6 , which indicates that they are all within a close range and fall within two classifications (Table 5 and Table 6). As depicted in Table 5 and Table 6 (classification of Discomfort Index), the discomfort in the Douala Metropolis at all seasons is always that in which most people suffer discomfort and also that in which everyone feels stress. The high THI values indicate that there are no comfortable or cold situations in Douala as no month was below $25^{\circ} \mathrm{C}$ even December month. According to (Hayward \& Oguntoyinbo, 1987), the months proceeding the rainy season, (February, March and April) had the most discomfort. And observation has shown too that the months of July and August tend to be less discomforting. In Douala, even October, November and December months also have high discomfort values (Figure 1). The relative humidity of Douala reaches its maximum point in July, August, September and October, after which it begins to decline and gets to its minimum in January and February, after which it begins to increase again. Figure 1 and Figure 2 summarizes the temperature and relative humidity pattern for Douala Metropolis.

Based on the findings of this study (Table 5 and Table 6; Figure 1 and Figure 2 ), the level of discomfort experienced by the people of Douala revealed they are always in discomfort by the climate. This is usually in the form of heat stress, heat stroke, heat crumps, meningitis, exhaustion, fatigue, headache, nausea, fainting and even death (Enete et al., 2014). Based on the responses from the respondents, a strong relationship between the land use types/cover, and heat related symptoms was ascertained. The result revealed the inhabitants of Douala hold a strong perception of temperature changes in the Douala and its health implication. It was observed that about $99.2 \%$ of the households sampled confirmed that there has been a change in the temperature of the area while $0.4 \%$ are of the view that no changes have taken place and the remaining $0.4 \%$ were indifferent to their knowledge of temperature variation in the area (Table 7). As seen in Table 4, of the 248 respondent who were of the view that there is a change in temperature further affirmed that the change has been towards an increase, 201 further confirmed the increase in temperature was highly noticed in the month of February and March. This increase in temperature in the month February and March may be because of the fact that these months represent the heart of the dry season in the tropical regions. Generally, the result shows that 


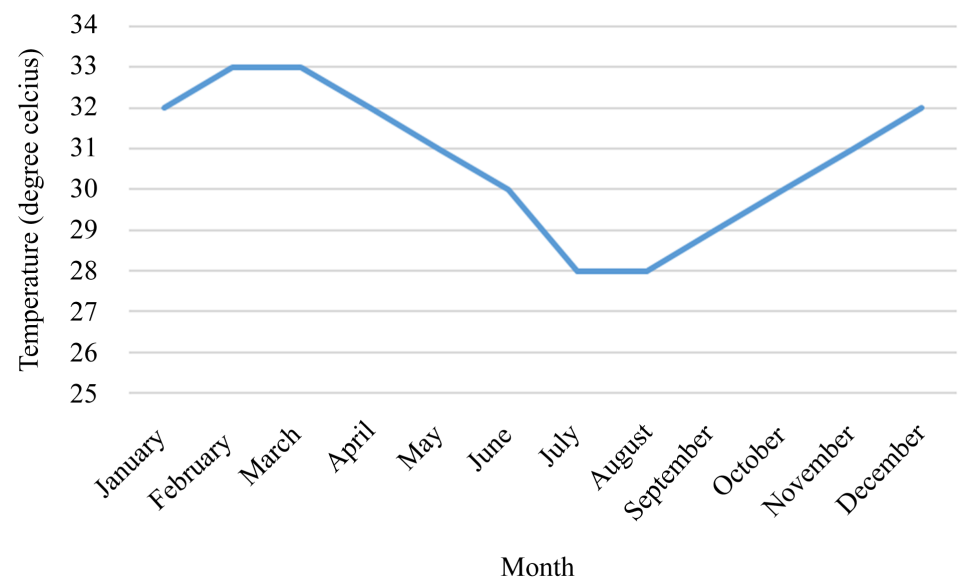

Figure 1. Showing the distribution of mean monthly behavior of temperature in Douala.

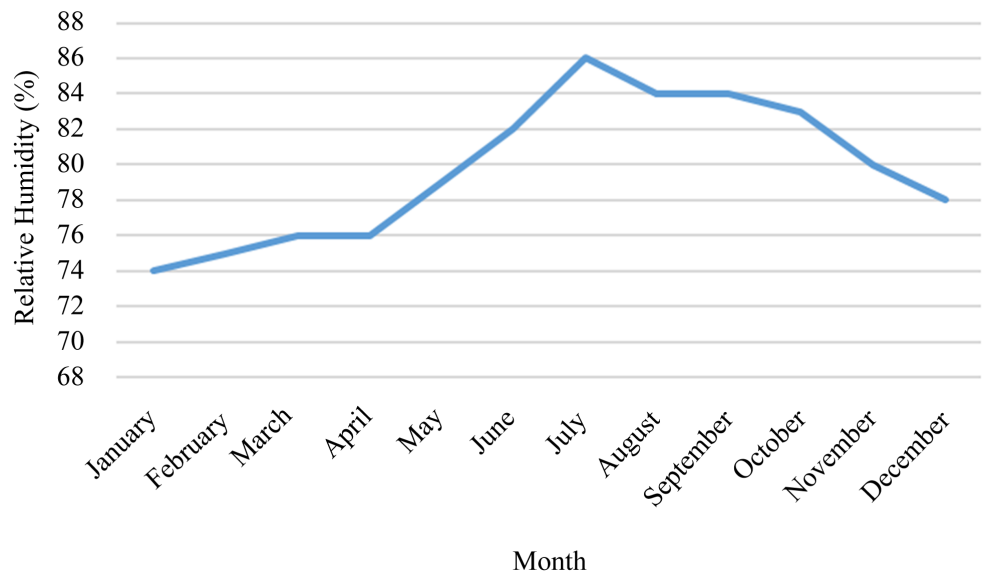

Figure 2. Showing the distribution of mean monthly behavior of R.H in Douala.

Table 7. Perception of the people in respect to temperature change.

\begin{tabular}{|c|c|c|c|c|}
\hline Questions & $\begin{array}{l}\text { Responses } \\
\text { (yes) }\end{array}$ & $\begin{array}{l}\text { Responses } \\
\quad(\mathrm{No})\end{array}$ & Indifferent & Total \\
\hline $\begin{array}{l}\text { Has there been a change in the temperature } \\
\text { of Douala? }\end{array}$ & $248(99.2)$ & $1(0.4)$ & $1(0.4)$ & $250(100)$ \\
\hline Has it been increasing? & $248(99.2)$ & $1(0.4)$ & $1(0.4)$ & $250(1000$ \\
\hline Was the change noticed in Feb./March & $201(81.04)$ & $45(18.15)$ & $2(0.81)$ & $248(100)$ \\
\hline $\begin{array}{l}\text { Does the increase in temperature make you or } \\
\text { members of your household uncomfortable? }\end{array}$ & $240(96)$ & $6(2.4)$ & $4(1.6)$ & $250(100)$ \\
\hline
\end{tabular}

$96 \%$ of the household uphold that the increase in temperature makes them uncomfortable since it increases the number of heat-related symptoms and illnesses (Table 7).

\subsection{Urban Heat Island Coping Measures}

Extreme heat has a direct relationship between urban heat island and human discomfort since extreme heat situation result to high level of discomfort in man. 
A direct relationship between urban heat island and human discomfort in the Douala Metropolis of Cameroon was observed. The findings of this study revealed that increase in urban heat island situation in the Douala metropolis have a significant impact on the health of the people especially in terms of discomfort and the spread of heat related symptom and illnesses (Enete et al., 2014). The findings of this study further revealed that the inhabitants of Douala adopted different strategies to reduce the effect of urban heat island. The various coping strategies adopted by all households include, stay indoors, drink plenty of water, wear light clothing, go to an $\mathrm{A} / \mathrm{C}$ location, take a cool shower, avoid outdoors, wear a hat or cover head. Their reaction to the above coping strategies included:

1) Always (at all times: Used to indicate that something happens or is done continuously, repetitively, or on every occasion);

2) Most of the time (indicating nearly all or the majority of the time);

3) Sometimes (Occasionally i.e. from time to time, not continually or every time);

4) Rarely (almost never or not very often);

5) Never (at no time in the past or the future).

Their reactions vary considerablely among the different coping strategies. A correlation between coping strategies and the reaction shows that the respondents always adopt coping strategies to reduce the impact of UHI (Table 8). From Table 5, the frequency, drinking plenty of water, which refers to an increase in the amount of water intake, was the most widely used mitigation measure. All 250 questionnaires in the area cited always as their best reaction (that is they always drink plenty of water) as far as drinking plenty of water is a concern. The rate of citation of staying indoor (within the confines of the house) varies considerablely across the responses (always, most of the time, sometimes, rarely, and never). A majority of respondents cited sometimes (30\% with 75 citations), followed by most of the time with 24\% (60 citations), rarely with $19.6 \%$ citations), always (17.2\% with 43 citations). The reaction in terms of wearing of light cloth shows that, a greater number of the respondents (140) were of the opinion that wears light clothes during periods of high temperature.

Table 8. Urban heat island coping measures.

\begin{tabular}{cccccc}
\hline Strategies & Always & Most of the time & Sometime & Rarely & Never \\
\hline Stay Indoor & $43(17.2 \%)$ & $60(24 \%)$ & $75(30 \%)$ & $49(19.6 \%)$ & $23(9.2 \%)$ \\
Drink Plenty of water & $250(100 \%)$ & 0 & 0 & 0 & 0 \\
Wear light clothing & $47(18.8 \%)$ & $46(18.4 \%)$ & $140(56 \%)$ & $16(6.4 \%)$ & $1(0.4 \%)$ \\
Go to A/C Location & $15(6 \%)$ & 0 & $52(20.8 \%)$ & $155(62 \%)$ & $28(11.2 \%)$ \\
Take a cool showers & $147(58.8 \%)$ & $66(26.0 \%)$ & $12(4.8 \%)$ & $5(2 \%)$ & $20(8 \%)$ \\
Avoid outdoors & $52(20.8 \%)$ & $85(34 \%)$ & $68(27.2 \%)$ & $30(12 \%)$ & $15(6 \%)$ \\
Wear a hat or cover head & $32(12.8 \%)$ & $23(9.2 \%)$ & $128(51.25 \%)$ & $35(14 \%)$ & $32(12.8 \%)$ \\
\hline
\end{tabular}


It was also revealed that due to the expensive nature of $\mathrm{A} / \mathrm{C}$, most of the respondent (155) shared the view that they rarely use $\mathrm{A} / \mathrm{C}$ as a reactive measure while 52 indicated that they use A/C some of the time, 28 never.

\subsection{Discussion of Findings}

The findings of this study reveal a relatively higher temperature compared to its surrounding rural area. Both anthropogenic and natural factors were cited as motivating factors of the difference in temperature in the selected transects of the Douala metropolis. The anthropogenic factors identified were housing type/structure, nature of the surface, nature of vegetation cover and economic and commercial activities. A significant relationship was observed between land use type (residential, commercial, industrial and administrative), distance from the $\mathrm{CBD}$ and temperature. Areas further away from the $\mathrm{CBD}$ recorded lower temperatures compared to areas closer to the $\mathrm{CBD}$. Banamoussadi, which is about $8 \mathrm{~km}$ away from the $\mathrm{CBD}$, recorded the lowest temperature of $34.9^{\circ} \mathrm{C}$ while Akwa, which is found in the $\mathrm{CBD}(0 \mathrm{~km})$, recorded a temperature of $37.1^{\circ} \mathrm{C}$. This is because an increase in population, traffic flow and the present of huge modern buildings and pave surfaces modify the temperature of the area. Despite the influence of distance from the $\mathrm{CBD}$, it was also observed that the nature of the land use had a great significance on the temperature in the area. Industrial zones often referred to as free trade zone recorded the highest temperature of over $38^{\circ} \mathrm{C}$. This is because the industrial space constituted an economic force, which attracts a population of both skilled and unskilled job seekers. They equally use energy for production and produce greenhouse gases that influence temperature around their location. Moreover, they create pockets of high temperature around their site thereby contributing to UHI. Commercial land uses were next to industrial land uses with temperatures ranging $36^{\circ} \mathrm{C}-37^{\circ} \mathrm{C}$. This increase in temperature can be attributed to high population density and diverse human activities. This population concentration of the area and the present of large markets contribute significantly to the establishment of pockets of high temperature leading to an increase in UHI. Residential areas recorded the lowest temperature of less than $36^{\circ} \mathrm{C}$. This is because these regions contain mostly settlements with little or no commercial activities.

The extern of vegetation cover equally plays a significant role in modifying the microclimate in each transect. Site LVR (GRA) had a more fully developed vegetation canopy than site LOR (Bonamousadi), but other Land-use/Land-cover characteristics were similar. Comparing sites LVR and LOR can therefore reveal the effect of vegetation canopy on air temperature. During the day, vegetation-covered site LVR was $\left(1.5^{\circ} \mathrm{C}\right.$ and $\left.0.8^{\circ} \mathrm{C}\right)$ cooler than the reference site for both rainy season and dry season day time respectively. At night time, however, the trend reversed with LOR being only $\left(1.7^{\circ} \mathrm{C}\right)$ cooler than the reference site and LVR only $\left(0.65^{\circ} \mathrm{C}\right)$ cooler. Furthermore, LVR sites rapidly heated up as the night progressed. 


\subsection{Conclusion}

The present study explored the effects of land-use/land-cover types on intra-urban air temperature variations under different atmospheric stability conditions, using paired measurement program. The result shows that temperature in the area has been on a considerable increase and such increase, has led to a modification of the other climatic elements and a modification of the heat island situation. The month of February recorded a maximum temperature of $32.6^{\circ} \mathrm{C}$ and a minimum temperature of $25^{\circ} \mathrm{C}$ giving a temperature range of $7.6^{\circ} \mathrm{C}$ while the month of March recorded a maximum of $32.3^{\circ} \mathrm{C}$ and a minimum of $24.6^{\circ} \mathrm{C}$ giving a range of $7.7^{\circ} \mathrm{C}$. During the rainy season, the month of June recorded a maximum of $30^{\circ} \mathrm{C}$ and a minimum of $24^{\circ} \mathrm{C}$ giving a range of 6 while the month of July recorded a maximum $28.3^{\circ} \mathrm{C}$ and a minimum of $24.4^{\circ} \mathrm{C}$ giving a range of $3.9^{\circ} \mathrm{C}$. The temperature range shows that the Douala metropolis experiences a significant high temperature almost all year round. The urban heat island situation emerges as a result of the increase in temperature in the Douala urban space. The result shows that the inhabitants use various coping strategies to adapt to UHI. The strategies identified include, stay indoors Drink plenty of water, wear light clothing, go to an A/C location, take a cool shower, avoid outdoors, and wear a hat or cover head. The widely used coping strategy identified is drinking plenty of water. The expensive nature of $\mathrm{A} / \mathrm{C}$ makes it the least use coping strategy.

\section{Conflicts of Interest}

The author declares no conflicts of interest regarding the publication of this paper.

\section{References}

Awuh, M. E., Officha, M. C., Okolie, A. O., \& Enete, I. C. (2018). A Remote Sensing Analysis of the Temporal and Spatial Changes of Land Surface Temperature in Calabar Metropolis, Nigeria. Journal of Geographic Information System, 10, 562-572. https://doi.org/10.4236/jgis.2018.105030

Baker, L. A., Brazel, A. J., Selover, N., Martin, C., McIntyre, N., Steiner, F. R. et al. (2002). Urbanization and Warming of Phoenix (Arizona, USA): Impacts, Feedbacks and Mitigation. Urban Ecosystems, 6, 183-203. https://doi.org/10.1023/A:1026101528700

Basu, R., \& Samet, J. M. (2002). An Exposure Assessment of Study of Ambient Heat Exposure in an Elderly Population in Baltimore, Maryland. Environmental Health Perspectives, 12, 1219-1223. https://doi.org/10.1289/ehp.021101219

Besancenot, J. P. (1978). Le Bioclimatic human de Rio. In J. B. Suchel, E. Altes, J. P. Besancenot, \& P. Maheras (Eds.), Recherches de Climatologic en Milieu Tropical et Mediterrarean. Cahier No 6 du Centre de Recherches de Climatologic. University de Dijon.

Buchin, O., Hoelscher, M. T., Meier, F., Nehls, T., \& Ziegler, F. (2016). Evaluation of the Health-Risk Reduction Potential of Countermeasures to Urban Heat Islands. Energy Build, 114, 27-37. https://doi.org/10.1016/j.enbuild.2015.06.038

Centers for Disease Control and Prevention (2003). Heat Related Deaths-Chicago, Illi- 
nois, 1996-2001 and United States, 1979-1999. Morbidity and Mortality Weekly Report, 52, 610-613.

Enete, I. C., Awuh, M. E., \& Amawa, S. (2014). Assessment of Health Related Impacts of Urban Heat Island (UHI) in Douala Metropolis, Cameroon. International Journal of Environmental Protection and Policy, 2, 35-40. https://doi.org/10.11648/j.ijepp.20140201.15

Gartland, L. (2010). Heat Islands: Understanding and Mitigating Heat in Urban Areas. Routledge.

Harlan, S. L., Brazel, A. J., Prashad, L., Stefanov, W. L., \& Larsen, L. (2006). Neighborhood Microclimates and Vulnerability to Heat Stress. Social Science \& Medicine, 63, 2847-2863. https://doi.org/10.1016/j.socscimed.2006.07.030

Hayward, D. F., \& Oguntoyinbo, J. S. (1987). The Climatology of West Africa (271 p.). Rowan \& Littlefield.

Hsieh, C. M., \& Huang, H. C. (2016). Mitigating Urban Heat Islands: A Method to Identify Potential Wind Corridor for Cooling and Ventilation. Computers, Environment and Urban Systems, 57, 130-143.

https://doi.org/10.1016/j.compenvurbsys.2016.02.005

Oke, T. R. (1997). Urban Climates and Global Environmental Change. In A. Perry, \& R. D. Thompson (Eds.), Applied Climatology: Principles and Practice (pp. 273-287). Routledge.

Rebetez, M., Dupont, O., \& Giroud, M. (2009). An Analysis of the July 2006 Heatwave Extent in Europe Compared to the Record Year of 2003. Theoretical and Applied Climatology, 95, 1-7. https://doi.org/10.1007/s00704-007-0370-9

Ruddell, D. M., Harlan, S. L., Grossman-Clarke, S., \& Buyantuyev, A. (2010). Risk and Exposure to Extreme Hear in Microclimates of Phoenix, AZ. In P. S. Showalter, \& Y. Lu (Eds.), Geospatial Techniques in Urban Hazard and Disaster Analysis. Geotechnologies and the Environment (Vol. 2, pp. 179-202). Springer. https://doi.org/10.1007/978-90-481-2238-7_9

Tzenkova, A., Kandjov, I., \& Ivancheva, J. (2003). Some Biometeorological Aspects of Urban Climate in Sofia. Proceedings of 5th International Conference on Urban Climate, 2, 103-106. 